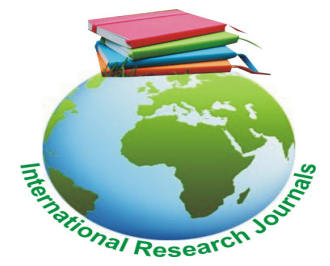

International Research Journal of Arts and Social Sciences, Vol. 2(9) pp. 213-219, October, 2013 DOI: http:/dx.doi.org/10.14303/irjass.2013.044

Available online http://www.interesjournals.org/IRJASS

Copyright (c) 2013 International Research Journals

Full Length Research Paper

\title{
Decolonising the Museum: The Case of Zimbabwe Military Museum in Gweru
}

\author{
${ }^{*}$ Forget Chaterera and Dr VZ Nyawo \\ Department of Archaeology, Cultural Heritage and Museum Studies and Department of History, \\ Midlands State University \\ *Corresponding Authors Email: 47703261@mylife.unisa.ac.za
}

Accepted 20 August, 2013

\begin{abstract}
The Zimbabwe Military Museum in Gweru seems to be struggling to come out of the colonial shell in which it was established. The permanent collection on display represents the kind of legacy which elevates the white settler ideologies. Through objects on display, supported with English text panels, the Zimbabwe Military Museum documents and memorialises in a seemingly celebratory manner, the colonial dominance. The task of this paper is to advocate for a national museum that claims both the past and the present to construct a decolonised future for the local indigenous people. As public institutions whose purpose in life is to serve the public, museums in Zimbabwe need to seriously consider offering services that are meaningful and relevant to the local indigenous communities. For that noble obligation to be fulfilled, the local indigenous communities should be actively involved in museums' programmes and activities. Using the qualitative and quantitative methodologies the paper examines the Zimbabwe Military Museum's exhibitions, analysed the literature that goes with it and interviewed users and officials of the Zimbabwe Military Museum.
\end{abstract}

Keywords: Colonial Ideology, Dark History, Documentation, Indigenous Communities, Representation.

\section{INTRODUCTION}

National museums in Africa were established during the colonial era to house objects that best served the interests of imperial agents (Foley 2000). The colonial ideology of a museum perceived the local indigenous people as backward and primitive and is therefore treated as a dark history in this paper. Thirty three years of independence, the Zimbabwe Military Museum (ZMM) continue to be dominated by colonial objects and guided in its operations by the colonial ideologies of what constitutes a museum. That has distanced the museum from potential visitors and alienated the local populace from their history. Decolonising the mindset of a museum professional could be the starting point of better serving the Zimbabwean society. It is acknowledged that the development of museums throughout Africa coincided with the emergence of colonialism and imperialism (Foley 2000). Colonialism was inextricably linked with the ideas of researching exotic lands and their populations and establishing what was referred to as 'positional superiority' of the colonizers (Said 1978). This paper initiates a discussion into decolonizing the Zimbabwe
Military Museum through exhibiting collections that represent well the interests of the local indigenous populace as well as adopting programmes and activities that are shaped and informed by members of the public.

\section{About the Zimbabwe Military Museum}

ZMM is situated in Gweru which is Zimbabwe's third largest city. The Zimbabwe Military Museum in Gweru serves as the country's National Army and Aviation Museum. The museum has a total of seven galleries namely the military history gallery, the foyer, armored vehicle hanger, police gallery, guinea fowl memorial hut and the artillery hanger. Receiving the eye of the visitor at ZMM are two massive principal tanks which are placed a few meters away from the museum's main entrance. To the right is the Stuart M-3 MK1 (USA) tank which was used by the allied forces in North Africa. To the left is the T34 USSR tank which was used by the Russians on the eastern front against the German Panzers. Already, from 
that outside setting of the museum, it may be questioned what it is that is Zimbabwean about the museum (Mtombeni 2011). The environment receiving the visitor is not reflective of the 'Zimbabwe Military History' as is suggested by the name of the museum and as should be the case. The outside environment is what people see as they pass by and probably influence their decision on whether to pay a visit to the museum or not. The external environment should therefore send the right message by looking relevant to the community it purports to serve.

\section{Background to the study}

Upon attaining independence, it is expected of every country to abolish ways that promote the interests of the colonisers at the expense of the local indigenous people. Such developments are not only restricted to the economic and political functions of a country but stretch to how cultural institutions such as museums serve the public. As observed by Mupira (2012:2), museums in Zimbabwe have been under scrutiny but this has mainly been from a very tiny academic fraternity, largely university students in their dissertations. The implication is that museums in Zimbabwe have not received much pressure for change in the way the past is presented. To that effect, Mupira (2012:14) commented that museum efforts to decolonise their practices have been internally driven, at own rather slow pace. Moreover, changes done in museums do not reflect local content and are heavily influenced by the western conceptual frameworks of display. In that light, this paper sought to establish the extent to which ZMM is representing the local indigenous people. Does the museum depicts the military history of Zimbabwe?

Museum professionals in Africa lament the lack of audience research to determine what people would want to see. The lack of audience research has been held responsible for gluing national museums in Africa to the western ways of thinking. At its emergency in the early $1900 \mathrm{~s}$, the museum was the work of colonial administrations in search of objects to display at colonial and world exhibitions (Rappaport 1998:87). Their aim was to charm the population in the home country with the exoticism and folklore of African countries, and in so doing, justify their presence there. These places we call museums, designed as they were for foreigners and tourists and which claimed to present a cultural overview of the country, were constructed in the style typical of official colonial palaces. The Zimbabwe Military Museum was established in the early 1960s through the efforts of Mrs Boggie, Mr Fyfe and other members of the pioneer settlers. The museums' link with the colonial period remained vividly depicted in the exhibitions showcased in the museum. The culture and ideologies of the Zimbabwe's colonial past are strongly memorialised. This paper is not denouncing the displaying of Zimbabwe's painful and dark histories. What is loathed and denounced by the paper is the perpetuation of colonial ideologies that alienates the local indigenous people from their heritage.

European dominance remained evident in the national borders, political infrastructures, education systems, museums and art galleries national languages, economies, and trade networks of each nation (Fogelman: 2002:21). It is socially and psychologically unhealthy for our museums to continue operating within the boundaries set by the Europeans, mostly to suit their needs. That justifies the call for this paper to work in the direction of abolishing the colonial ideology in our museums. Schwartz $(1992: 138)$ notes that museums in contemporary Africa are largely the product of European colonialism. Many were founded or had their collections amassed during the imperial era, by foreigners. Such is the case with ZMM as the majority of their collections were donated to them by the Rhodesian forces mostly to perpetuate their colonial supremacy. It is this colonial legacy that is cited as a principle factor to explain the irrelevancy of museums to the contemporary African communities they purport to serve (Konaire 2000; Nettleford 2010, Shepherd 2002 \& Mupira 2012).

\section{Statement of the problem}

The independence of the mind has not yet been granted to the Zimbabwean museum professional. Thirty three years of independence, our museums are still paying allegiance to the so called 'standard' museum practices set by the Europeans. These disable the important and locally relevant function of a museum. Through their classification systems, arrangement and description of objects, ZMM continue to glorify the western concepts of a museum. That has distanced the cultural institution from the wider indigenous populace, hence defeating the purpose in life of a museum. The political visibility in museums and their struggle to support indigenous identities is because museums might be under new management but they have remained structured according to their older colonial origins. The liberation and independence of the mind is urgently required.

\section{Review of related literature}

The colonial ideology informs the design of museum exhibits in three governing concepts that have been identified by (Fogelman 2002:22) as the boundary, the label, and the meta-narrative. The boundary permits the classification of collections according to time and space essential to colonialism. The label demonstrates that the unknown is known, and that the world can be ordered and the meta-narrative is also crucial because it establishes the authority of the institution as well as the 
positional superiority of the colonisers. Combined together, these three concepts shape the exhibits of the colonial museum, normalising the power relations found in cultural dominance. Challenging the boundary, the label and the meta-narrative concepts is an essential step in the decolonization of the museum (Shepherd 2002: 78). Informed by that philosophy, this paper examines the three concepts as they are portrayed in the ZMM

Notable attention is beginning to be realised within the academic circles on the need to dismantle the colonial ideology in our national museums in Zimbabwe. From the eastern region, the curator for the Museum of Transport and Antiquities 're-thought the notion of a museum and its utopian ideologies in a post-colonial state'. Chipangura (2012:8) laments the colonial nature of the Museum of Transport and Antiquities in Mutare and denounces the Beit Gallery at the Museum for failing to represent anything meaningful to the visitor. The Beit gallery contains transport artefacts, some zoological specimens, and an observatory beehive with live bees, a section with kitchen utensils, a section with a traditional healer, bows and arrows and an archaeological and geographical section. All those are exhibited in one gallery and do not attempt to tell any meaningful story to the visitor. Much of the ethnographic artefacts are on the floor in this gallery and displayed as strange, exotic and devoid of any social and historical significance to the way of life of the people. The gallery is a mixture of a lot of different types of artefacts which do not talk about a related theme or subject. The objects were simply bunched together for the need of ethnographic inquiries. Chipangura (2012:10) indicated that failure to change the set up of the gallery as an entertainment platform for the tiny leisured elites of the colonialists has led people to view the museum with scepticism as the indigenous people's own culture continue to be derided by the misconstrued old exhibitions that still portray aspects of a colonised Zimbabwe.

The need to decolonise our museums is not a new call. Mupira (2012:3) notes that soon after independence the response by museums to the colonial dominant ideas was to remove the offending displays and labels glorifying European domination. However, the displays were not replaced by something ingenious. Notable changes were done to the labels and texts. For example, the Queen Victoria Museum became the Zimbabwe Museum of Human Sciences, Bushmen became San/Khoisan, 'Rhodesians at War' changed to 'Zimbabweans at War' and so forth. However, Mupira (2012) indicates that at Mutare Museum the demeaning and thematically out of context bushmen display has not changed and the same topic at the Museum of Human Sciences still uses colonial discourse. Additionally, Mupira (2012:7) observes that most of the exhibitions mounted in the 1960s have not changed as they still occupy the same space, with the same limited content, context and explanation. Guided by that argument, the present paper looked into whether exhibitions at ZMM changed when the country attained independence and to establish the relevance of changes to the local indigenous people.

An assessment of the sentiments provided in works such as those by Chipangura (2012) and Mupira (2012) communicate that museum practices adopted and borrowed from colonial museology are still evident in Zimbabwean museums and have contributed to produce a uniform image of museum displays. On that note, the current paper sought to establish ways in which ZMM may successfully transform its exhibitions so as to become relevant to the wider community. That demands an ideological refocusing, abolishing the elitist taste and dogmatic interpretation that are done without involving the intended recipients of the museum services.

\section{What is decolonization?}

Decolonisation is a widely used concept both inside and outside the academic circles. Despite the wide use of the term, the meaning of decolonization is still unclear and debatable. Some commentators use 'decolonisation' to mean the process by which empires disintegrate and colonies achieve independence (Smith 1999 \& Smith 2008). Scholars in developing countries now often consider decolonisation as a process of struggle for ending colonial rule (Smith and Wobst 2005). From this vantage point, decolonisation means liberating colonies, whereas in the West it usually means granting independence. The substance of decolonisation is the actions of the colonial power, including all the strategies, tactics and measures used in the course of a forced imperial retreat, which were taken with the intention of maintaining its own interest.

Within the museum context, decolonization refers to granting the locals active voice in museum's programmes and activities. As alluded to earlier on, in Zimbabwe, upon the attainment of independence, names were changed with the Rhodesia Military Museum becoming the Zimbabwe Military Museum. Nonetheless, changing names without changing policies and ways of operating may not be adequate for a Zimbabwean who long to be offered the 'Military History of Zimbabwe'. As such, it can be observed that decolonization is grounded in the rights of the local indigenous people.

\section{METHODOLOGY}

This article sought to investigate how far ZMM has gone towards offering services that are meaningful and relevant to the local indigenous communities. The investigation employed the survey research design and used the triangulation technique. The investigator analytically observed seven galleries at ZMM paying 
attention to the three concepts (boundary, label and meta-narrative) that uphold the colonial ideology of a museum. Interviews were held with the Zimbabwe Military Museum curator and one of the tour guides as well as the front desk personnel. A mini self administered questionnaire was given to two visitors who happened to have visited the museum on the day the investigator went to tour the museum. The visitors' comment book was also made use of.

\section{FINDINGS AND DISCUSSIONS}

The entrance to the first gallery (Military History Gallery) at ZMM is to the right of the front desk. The Military History Gallery has detailed graphics of the wars of freedom fought in Zimbabwe during the last thousand years. Considerable efforts are noted in the Military History Gallery as the two key architects of the Chimurenga (Mbuya Nehanda and Sekuru Kaguvi) and the Ndebele king Lobengula are displayed at the entrance of the Military History of Zimbabwe Gallery, signifying their importance during the liberation struggle. The gallery has pictorial illustrations and profiles of nationalists such as Comrade Josiah Chinamano, Herbet Chitepo, Leopold Takawira and the first Heroine Amai Sally Mugabe. While that may be commendable to an extent, it is sad to note that ZMM continue to uphold the elitism ideology of a museum by giving attention to those who occupied the upper class in the social stratification system. The Military History Gallery concentrates on the elite or dominant figures in the liberation struggle. The masses that were the pillars of the struggle organising strikes in towns and supporting the fighters in rural areas are invisible. The war veterans who were at the battle front; ex-political prisoners, detainees, vanamukoma, chibwidos and mujibahs are absent. The gallery is clearly a history of the dominant and their achievements. As concurred by Mupira (2012:14) the practice of museum display is still embedded in the elitist cultural background of the 19th century. The history in our museums should not only be that of the powerful alone for they may have never been that powerful without the support of the masses. From the Military History Gallery, it was observed that the western way of thinking still dominates the museum. The observation made by the investigation is consolidated by Fogelman (2002:20) who noted that African museums were born as elitist and paternalistic institutions, and were alien to indigenous populations. That has indeed sadly remained the case with ZMM.

Remarkable improvements were also noted in the Police Gallery. The sequencing takes us to the Independence era. The command is displayed from 1903 to the present Commissioner General Augustine Chihuri

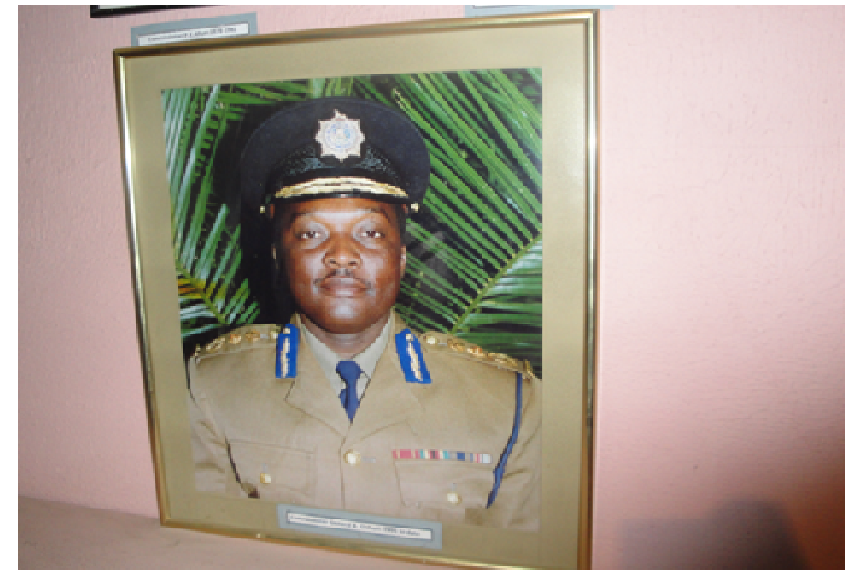

However, as is the case with the Military History Gallery, the Police Gallery focus solely on dominant figures. The findings from the Guinea Fowl Memorial Hut Gallery revealed that ZMM failed to move away from where it was left by the Europeans. The gallery has illustrations of the Guinea Fowl School head masters, school captains and house heads from 1947 to 1978 . No attempts were made to continue the captions and that is detrimental to the present Guinea Fowl student and the community at large as they may be compelled to assume that those who are depicted are the most important.

In an interview held with the director for Gweru Military Museum (Mr Nhutsve), it was confirmed that the same objects which were donated by the Rhodesian forces are still being used to tell different stories. While there is nothing bad about reminiscing our 'dark history' for the purposes of knowing where we came from, it becomes a cause for concern when the colonial objects tend to dominate the local indigenous objects. In addition, the curator for ZMM informed the study that most of the colonial objects are still in use but these have however been re-arranged and re told. The manipulation of objects donated by the white settlers to tell the Zimbabwean story is subject to intense criticism especially with regards to provenance issues. For instance, the aviation gallery is dominated by displays that show case the royal flying corps, royal Rhodesian air force, the Rhodesian Air training group, the Rhodesian Sons 1940-1945 and ends with a single display of the air force of Zimbabwe. The Zimbabwean air force after independence up to date is absolutely The museum has failed to keep the public abreast of the developments on the aviation of Zimbabwe. The aviation gallery has remained static and failed to move away from the colonial background in which it was established.

The galleries at ZMM are all permanent exhibitions except for the foyer (the gallery which is around the reception area). While it was a relief to observe uniforms that were used by liberation fighters, it is sad to note that these seem not to have a permanent place in the 
museum as they are displayed in the temporary exhibition area. In interviews held with museum officials it was revealed that the exhibition was only two weeks old and will be removed after two months as is the norm with all temporary exhibitions. The first display in the foyer is a ZIPRA forces' uniform which was captured during the attack on Dr Joshua Nkomo's house in Lusaka. Another display in the foyer is the famous figure 8 boots which was used by the ZANLA forces. There is also a Chinese Rice Uniform which was donated to ZANLA forces during the liberation war and a Soviet Socialist Republic uniform which was donated to the ZIPRA forces. The temporary exhibition at the foyer was evident of the military history of Zimbabwe and should have been given a permanent place in the museum for the benefit of the local indigenous people. The museum is failing to challenge the existing setup of the museum which is largely dominated by colonial objects. Objects that are of much relevance and significance to Zimbabweans are treated

as 'temporary exhibitions' and plenty of other objects that are more meaningful to the indigenous people such as uniforms that were worn by Chibwidos are locked up in the Joc Hut storage facility and are not open for public viewing. Removing the colonial objects in the permanent exhibitions seem to be an abominable move. This paper is certainly not advocating for a total removal of colonial objects as they are indeed part of the Zimbabwean history. However, it becomes a cause for concern when artifact types privileged as exemplary of cultural heritage during the colonial era continue to dominate the collection. Artefacts collected post-independence at the ZMM have tended to imitate rather than to diversify the colonial collection.

The failure to represent the Zimbabwean nation by the ZMM is also evident at the aviation museum. On hangers are FB9 vampire planes which never participated in war. In an interview held with Rtd. Lt. Col Mtombeni, it was revealed that the FB9 vampire planes were grounded in 1954. On the hangers is also the Harvard MK-24A: trainer and the De-Havilland Vampire T11-trainer which were never used by the freedom fighters. However, the call to have planes that were used by fighters on display is debatable as there seem to be conflicting arguments from the eyewitnesses and liberation war participants. For instance, some war veterans reported that planes that were used by the freedom fighters were destroyed at Thornhill air base in 1982 and most if not all of their uniforms were also burnt at Inkomo barracks. Conversely, one of the tour guides at the aviation Mr. Gumbo informed this study that the Zimbabwean liberation fighters never used planes as they heavily relied on the ground force. Such discrepancies in information and the uncertainty that visitors leave the museum with demonstrates failure by ZMM to research on issues that matter most to their mandate. Moreover, museums are not supposed to be glued in the past. They should seek to serve the contemporary society by presenting exhibitions using objects that are current and more meaningful to them. To that effect, the aviation gallery at the trim park museum could have done better by adding on to its collection some of the air crafts used in Zimbabwe since 1980 to date. A more closer and active involvement with the local indigenous community might have gone a long way in producing exhibitions that are relevant to the community. Even if the aviation gallery is reported to be an incomplete project, the argument of the gallery being strongly colonial in nature still stands as it is dominated by planes that were used by the Rhodesian forces.

ZMM is surely struggling to come out of the colonial shell in which it was established. All labels found in the seven galleries of the museum are written in English and this leaves the visitor to construct their own story concerning the exhibitions and losing the real meaning in the end. The most immediate and practical change that must be implemented with these exhibitions is proper relabeling. Furthermore some displays do not have titles and introduction panels to orient the visitor with these exhibitions. The labels that are present are not properly done; some of the text is invisible and is written in English with no specific explanations. In terms of the language the appropriate and feasible change should see a direct translation of all the text into vernacular languages so that it suits the local indigenous people. That way people will not continuously feel alienated from some of their cultural objects on display.

As agreed by Mupira (2012:15) Although recent museological thinking has led to some changes in the outlook of displays, most of them still look like their stereotypes in the traditional museum. The reason for this state of affairs can be attributed to lack of critical theory to approach museology, inability by museums to implement radical changes because they want to retain orthodoxy and generally lack of resources to meet all the activities related to democratization of the practice of museum display. The development of museums in Zimbabwe requires a strategic orientation so that attempts to decolonise their outlook are approached systematically. The museums should find modes of interpreting, presenting and promoting the cultures of Zimbabwean people in a manner that enhances understanding of the past and the present. There is no way they can continue to ignore the socio-political context in which they operate; otherwise they will remain unknown and irrelevant.

Many indigenous people still see museums loaded with association of colonialism, cultural repression and loss of their heritage. There is too much emphasis of the colonial rule at ZMM. The third gallery which is the 'Armoured Vehicle Hanger' is filled with objects that were used by the white settlers. These include the $4 \times 4$ field artillery tractor which was used by the Southern Rhodesian army, the Marmon Herrington Armoured Cars which were used by the Rhodesian training unit as well 
as the first and second Battalion Rhodesia regiment and the carrier T16 which was used by the royal Rhodesia air force for use on the bombing range in Kwekwe.

\section{The Marmon Herrington Armoured Car in the $3^{\text {rd }}$ Gallery at ZMM}

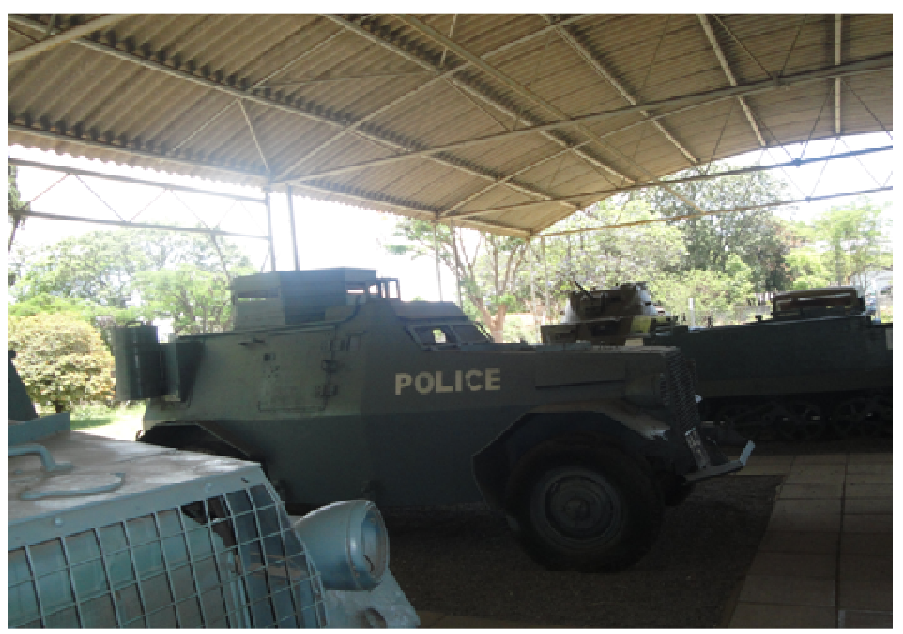

\section{CONCLUSIONS}

Exhibitions at ZMM are generally uninspiring. As informed by the curator at ZMM, the budget for producing new exhibitions is minimal, and the existing displays have in large part remained true to their initial installation. Once Zimbabwe attained independence, the ZMM did not challenge the goals of the educational and cultural systems inherited from the colonial administration. There is a growing need by the ZMM to rediscover its past and to assert its identity. Despite efforts made to train national technical staff, museums have remained institutions reserved for a minority of foreigners, tourists and intellectuals from urban areas. The museum is not in tune with local people's concerns; it has fixed our culture, deadened many of our cultural objects, and allowed their essence, imbued with the spirit of a people, to be lost. In light of that observation, this paper calls for an immediate decolonisation of the mind set in the ZMM. Museum professionals need to break free from all cultural alienation and rejecting foreign concepts. Our museums must be created in response to local needs, and not at the request of tourists or other foreigners. Thirty two years after independence, very little has changed at ZMM. The texts, labels, language, classification, arrangement and description of objects is largely informed by the western ways of what a standard museum should look like. The task of this paper was to initiate a discussion on how best ZMM can be representative of the communities it purports to serve. It is worthy acknowledging that demands and expectations from members of the public on how to decolonize the museum are as diverse and complicated as the different cultures that form the public. As such, the intention of this paper was to initiate a debate towards decolonizing the ZMM. That may see our museums in Zimbabwe gaining a wider recognition and acceptance from the local indigenous populace. Museums should symbolise and reinforce the incorporation of minority groups. Efforts have to be made towards liberating themselves from the western imperial setting. Museums should thrive to distance themselves from the ideology of colonialism and close divisions left by it (Brown 2002: 211). Long term exhibitions should be devoted to indigenous culture and museums should enhance the idea of unity through rejecting colonial ideologies and bring together different ethnic groups. To decolonise our museums, programmes and activities offered by our museums should be shaped by the voices of the indigenous people. The cutter's system of placing objects adjacent to other objects that share similar features should be challenged and be replaced by the indigenous knowledge systems. ZMM may do well if it adopts the open air concept. Open air museums represent a 'heritage of collective memory', and 'activities representing a whole set of concrete social practices in real-life situations'; in short, everything that gives these cultures life. The ZMM may want to assume responsibility over liberation heritage sites and use those as teaching vehicles and communication channels to the local populace. Pictorial displays of the popular battle fields such Dzapasi, Nyadzonya and Chimoio amongst others could have made ZMM more meaningful and relevant to the local indigenous communities.

\section{REFERENCES}

Brown M (2002). Representing the body of a nation: The art exhibitions of NewZealand's National Museum. http://www.dx.doi.org/1080/09528820110160709 (Accessed 20 August 2011).

Chipangura N (2012). Rethinking the notion of a museum and its ideologies in a post colonial state (Unpublished paper).

Duncan C (1995). Civilizing rituals: inside public art museums. New York: Routledge.

Fogelman A (2002). Colonial legacy in African Museology: The case of the Ghana National Museum. Museum Anthropology 31(1):19-27

Foley $G$ (2000). The enlightenment, imperialism, and the evolution of museums. The Koori History web site http://www.kooriweb.org/foley/essays/essay 3.html (accessed 10 November 2004).

Fox $P$ (1992). Memory, the museum and the postcolonial world. Meaning 51 (2): 308-18.

http://www.zhangshunhong.com/britishimperialismanddecolonisation.co

Konaire AO ( 2000). Towards a new type of ethnographic museum in Africa. Museum (138):146-151

Mtombeni N (2011). Museums must tell the Zimbabwean story. The Patriot Newspaper. Issue (7)

Mtombeni N ( 2011). Interviewed by F. Chaterera. Gweru, 25 August.

Mupira $P$ (2012). Dismantling the colonial legacy in Zimbabwean museums-thiry two years on (Unpublished paper).

Nettleford R ( 2010). Decolonising the spirit: the work of the creative imagination. Museum International61(4):35-40 
Rappaport J(1998). The politics of memory: native historical interpretation in the Columbian Andes. Durham \& London: Duke University Press.

Schwartz LK (1992). From the colonial museum to the museum of communities. Museum 175(3):137-141

Shepherd N (2002). Heading south, looking north: why we need a postcolonial archaeology. Archaeological Dialogues 9 (2): 74-82.

Smith LT (1999). Decolonizing methodologies: research and indigenous peoples. Dunedin: University of Otago Press.(provide page number)
Smith $C(2008)$. Decolonising the museum: the National Museum of the American Indian inWashington, DC. p. 424-440.

Smith C, Wobst HM (ed.) (2005). Indigenous archaeologies: decolonizing theory and practice. London and New York: Routledge.

Wobst HM (2001). Matter over mind: perishables and the glorification of materiality in archaeology, in P. Drooker (ed.). Fleeting identities: perishable material culture in the archaeological record: (43-57).

How to cite this article: Chaterera F and Nyawo VZ (2013). Decolonising the Museum: The Case of Zimbabwe Military Museum in Gweru. Int. Res. J. Arts Soc. Sci. 2(9):213-219 